Document downloaded from:

http://hdl.handle.net/10251/109812

This paper must be cited as:

Castillo López, M.; Montes Estellés, RM.; Navarro, A.; Segarra, R.; Cuesta, G.; Hernandez, E. (2008). Occurrence of deoxynivalenol and nivalenol in Spanish corn-based food products. Journal of Food Composition and Analysis. 21(5):423-427. doi:10.1016/j.jfca.2008.03.009

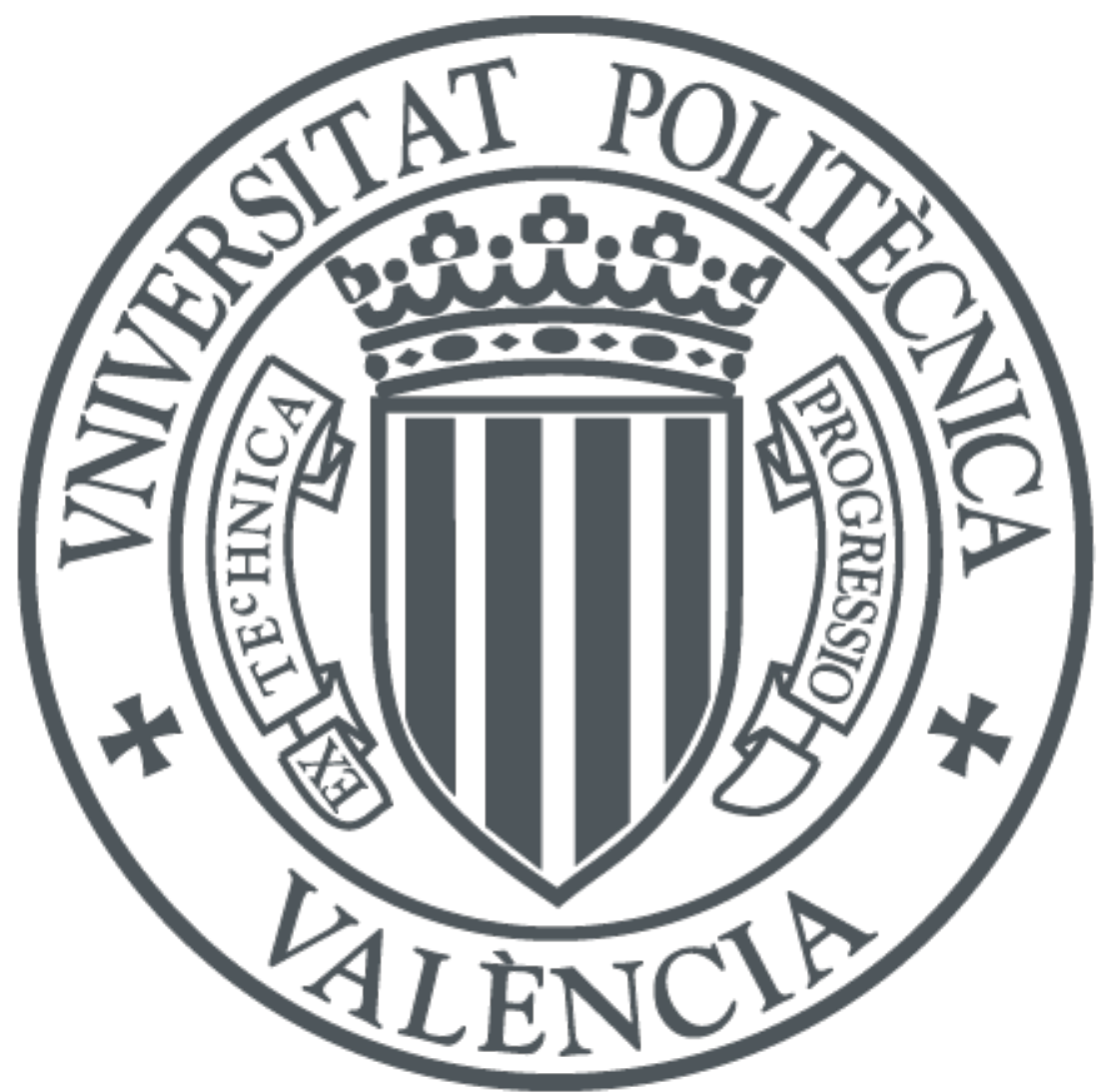

The final publication is available at

https://doi.org/10.1016/j.jfca.2008.03.009

Copyright Elsevier

Additional Information 


\section{Occurrence of deoxynivalenol and nivalenol in Spanish corn-based}

2 food products

3

4

5

6

7 María-Ángeles Castillo*, Rosa Montes, Adriana Navarro, Ramón Segarra, Gonzalo

8 Cuesta, and Enrique Hernández.

9

10

11 Departamento de Biotecnología, Escuela Técnica Superior de Ingenieros Agrónomos,

12 Universidad Politécnica de Valencia, Camino de Vera, 14, 46022 Valencia, Spain.

13

14 Runnig tittle: Mycotoxins in Spanish corn-based foods

15

16

17

18 * Corresponding author: María-Ángeles Castillo, Departamento de Biotecnología,

19 Escuela Técnica Superior de Ingenieros Agrónomos, Universidad Politécnica de

20 Valencia, Camino de Vera 14, 46022- Valencia, Spain

21 Fax: 34-963877429. Tel.: + 34-963877423.

22 E-mail address: mcastill@btc.upv.es

23

24

25 


\section{Abstract}

The aim of the present work was to evaluate the occurrence of trichothecenes toxins, deoxynivalenol (DON) and nivalenol (NIV), in samples of corn-based foods (breakfast cereals and snacks) consumed by the Spanish population. A total of 175 commercially available samples were randomly collected during 2005. Trichothecenes were determined by gas chromatography-electron capture detector. The estimated limit of quantification was $25.4 \mu \mathrm{g} / \mathrm{kg}$ for DON and $15.9 \mu \mathrm{g} / \mathrm{kg}$ for NIV. DON was detected in 22 of the 55 samples of breakfast cereals, in 13 of the 57 samples of baked corn snacks and in 12 of the 63 samples of fried corn snacks. NIV was detected in 6 samples of breakfast cereals and 1 sample of snacks. Based on total of samples, the median concentrations of DON and NIV found were 53.9 and $60.2 \mu \mathrm{g} / \mathrm{kg}$, respectively. The influence of different factors, such as the presence of additional ingredients and the type of commercial brand on the toxin incidence and content levels were also studied. The values of both mycotoxin intake found in this study are lower than the proposed Tolerable Daily Intake for the respective toxin ( 1 and $0.7 \mu \mathrm{g} / \mathrm{kg}$ bw/day for DON and NIV, respectively). 


\section{Introduction}

52

Deoxynivalenol (DON) and nivalenol (NIV) are type-B trichothecene mycotoxins,

that is, secondary metabolites produced by several fungal genera, most notably

Fusarium, which is known to attack various cereals. Surveys have shown that DON

occurs frequently in grains like wheat, barley, and maize, and that it is also the most common toxin, occurring concomitantly with 3-acetyldeoxynivalenol, 15acetyldeoxynivalenol and NIV (Tanaka et al., 1990; Trucksess et al., 1995; Placinta et al., 1999). Trichothecenes cause a wide range of toxic effects in animal and humans such as feed refusal, vomiting, diarrhea, hemorrhage, anemia and immunosuppression (Hussein and Brasel, 2001).

As the incidence of Fusarium toxins has been reported for cereals on a global scale (Placinta et al., 1999; JEFCA 2000, 2001; Schollenberger et al., 2007), regular contamination can be expected for grain-based foods as the food processing of cereal crops does not completely eliminate mycotoxins (Scott, 1991; Hazel and Patel, 2004;

66 Cetin and Bullerman, 2006). This has been confirmed for a variety of foodstuffs, 67 including breakfast foods, snack foods, bread, pasta, etc. (FSA, 2003, 2005;

68 Schollenberger et al., 2005a,b; Samar et al., 2007). As a result, humans are exposed to mycotoxins in their diet. It is clear that the presence of mycotoxins in the human diet, and especially in the diet of vulnerable populations like children, is a matter of concern.

In recent years the EU's Scientific Committee on Food (SCF) has evaluated the

72 Fusarium toxins DON (SCF, 1999), NIV (SCF, 2000), and a group of trichothecenes

73 (SCF, 2002). Likewise, the SCF established a tolerable daily intake (TDI) per kg of 74 bodyweight and day of 1 and $0.7 \mu \mathrm{g} / \mathrm{kg}$ for DON and NIV, respectively. In 2005, the 
European Commission (EC) set maximum levels of DON and zearalenone, which were

76

77 applied from July 2006 (EC, 2005a). No limits are established for NIV.

Despite corn being one of the more susceptible substrates to this type of contamination, there is a little information available on the occurrence of trichothecenes in corn-derived foods in Spain (Cerveró et al., 2007). The purpose of this study was to examine the occurrence and concentration levels of DON and NIV in Spanish cornbased foods, specifically breakfast cereals and snacks. Although there are currently no regulatory limits for NIV, their co-occurrence with DON and its toxicity justifies their inclusion in our studies. Other aims of this study were to estimate the daily intake of DON and NIV, and to assess the real contribution of cereal-derived foods to the TDI proposed by the SCF in the Spanish population.

\section{Material and methods}

\subsection{Reagents}

91 The trichothecene standards DON and NIV, lindane (Riedel-de-Haën ${ }^{\circledR}$ ) (internal standard) and derivatization reagent, Tri-Sil TBT (Supelco), a mixture of $\mathrm{N}$ trimethylsilylimidazole-N,O-bis(trimethysilyl) acetamide-trimethylchlorosilane (3:3:2) were purchased from Sigma-Aldrich (Madrid, Spain). Deionized water was purified with a Millipore Milli-Q Plus system (Millipore, Billerica, MA, USA). Potassium dihydrogen phosphate $\left(\mathrm{KH}_{2} \mathrm{PO}_{4}\right)$ and sodium hydroxide $(\mathrm{NaOH})$, used to prepare phosphate buffer, were purchased from Panreac (Barcelona, Spain). All solvents (acetonitrile and hexane) were analytical grade and purchased from J.T. Baker (Deventer, Holland). Stock and working standards of DON and NIV were prepared by 
100 appropriate dilution in acetonitrile to assess the linearity of method and spiked samples.

101 All stock solutions were stored at $-20{ }^{\circ} \mathrm{C}$ when not in use. The internal standard was

102 dissolved in hexane at $1 \mathrm{mg} / \mathrm{l}$ for GC-ECD measurements. The Mycosep ${ }^{\mathrm{TM}} 227$ columns

103 were purchased from Romer Labs, Inc., USA.

104 The standards of DON and NIV were purchased from Sigma-Aldrich as pure 105 mycotoxins. Krska et al. (2004) calculated the purity of commercially available DON 106 from Sigma, resulting in 496\%, and they concluded that these products can be 107 considered sufficiently pure for routine analysis of these mycotoxins in food and feed.

108 So we have used the standards as they were provided.

\subsection{Samples}

111

112 A total of 175 packaged samples of commercial corn foods were randomly collected

113 during the first 8 months of 2005 from supermarkets and retail outlets located in the city 114 of Valencia (Spain). A wide range of brands were covered to ensure that the survey was

115 representative of the range of products available to consumers in Spain. At least $0.5 \mathrm{~kg}$ 116 was collected for each commercial sample, which was finely ground for 3 min using an 117 Osterizer mill (Oster Co., USA) and was stored at $-20{ }^{\circ} \mathrm{C}$ until the moment of the analysis, according to Cirillo et al. (2003a,b).

119 The following food items were collected: corn-based breakfast cereals $(n=55)$, 120 baked corn snacks $(n=57)$ and fried corn snacks $(n=63)$. The sample collection was

121 divided to convenience of discussion into different groups on the basis of possible 122 ingredients and of the commercial brand type. The possible additional ingredients were 123 chocolate, butter, honey, wheat, oat, and aromatic flavours such as cheese, jam and 124 barbecue flavour. 


\subsection{Apparatus}

127

Mycotoxin analysis was performed using an Agilent 6890N gas chromatograph, equipped with a ${ }^{63} \mathrm{Ni}$ ECD (Agilent Technologies, Waldbrom, Germany). A fused-silica capillary column HP-5 [5\% methyl phenyl siloxane column (30 m x 0.32 mm i.d., 0.25 $\mu \mathrm{m}$ film thickness, Agilent Technologies)] was used. The carrier gas was nitrogen at a

132 flow of $1.8 \mathrm{ml} / \mathrm{min}$. The temperatures of splitless injection port and ECD were $250{ }^{\circ} \mathrm{C}$ and $300{ }^{\circ} \mathrm{C}$, respectively. The injection volume was $2 \mu \mathrm{l}$. The column temperature

134 program, following an initial period of $80{ }^{\circ} \mathrm{C}$ for $1 \mathrm{~min}$, was $30{ }^{\circ} \mathrm{C} / \mathrm{min}$ to $140{ }^{\circ} \mathrm{C}, 5$

$135{ }^{\circ} \mathrm{C} / \mathrm{min}$ to $280{ }^{\circ} \mathrm{C}$ and hold $31 \mathrm{~min}$. Signals were processed by HP GC ChemStation

136 software Version A.09.01 [1206] (Agilent Technologies, 1990-2001).

\subsection{Extraction and clean-up}

139

The mycotoxins were extracted and purified as described previously (Eskola et al., 2001) with few modifications. A $25 \mathrm{~g}$ subsample was extracted with $100 \mathrm{ml}$ of acetonitrile:water (84:16 v/v) into a $500 \mathrm{ml}$ Erlenmeyer flask. The flask was shaken with a rotary shaker at $170 \mathrm{rpm}$ for $80 \mathrm{~min}$ at room temperature, and filtered through a

144 filter paper (Whatman grade 2V) from Whatman (Maidstone, UK). The filtrate was 145 defatted with n-hexane (2x $20 \mathrm{ml})$. A total of $8 \mathrm{ml}$ of defatted extract was purified 146 through MycoSep 227 column, according to the instructions of the manufacturer. The 147 purified extract that passed through the column $(\sim 4-5 \mathrm{ml})$ was collected, and the 148 procedure was repeated by eluting the column with $8 \mathrm{ml}$ of acetonitrile:water (84:16 
$149 \mathrm{v} / \mathrm{v})$. The combined fractions were evaporated to dryness under a gentle stream of 150 nitrogen.

151

A $50 \mu \mathrm{l}$ volume of the derivatization mixture (TMSI-BSA-TCMS, 3:3:2) was placed into a vial containing the dry residue. The mixture was allowed to react for 30 min at $80{ }^{\circ} \mathrm{C}$. After cooling, the derivatized sample was diluted to $480 \mu \mathrm{l}$ with hexane and mixed thoroughly on vortex for $30 \mathrm{~s}$. The hexane was then washed with $1 \mathrm{ml}$ of phosphate buffer (0.1 M, pH 7.2) by mixing for about $30 \mathrm{~s}$ and, finally $20 \mu \mathrm{l}$ of internal standard (1 mg/l) was added and shaken on vortex. The two layers were allowed to separate. The upper hexane layer with the trimethylsilyl derivatives was transferred to a vial for the gas chromatographic analysis.

162

\subsection{Recovery assays, detection and quantification limits}

164

For recovery studies, mycotoxin-free samples were artificially fortified at three levels of each mycotoxin (50, 500, and $1000 \mu \mathrm{g} / \mathrm{kg}$ of DON, and 300, 500, and 2000 $\mu \mathrm{g} / \mathrm{kg}$ of NIV), as follows. Twenty-five grams of ground sample, previously defrosted, were soaked in $0.5 \mathrm{ml}$ of acetonitrile solution containing a suitable amount of each mycotoxin. Then the sample was submitted to dissolvent evaporation for $2 \mathrm{~h}$ at room temperature. Finally, the spiked sample was extracted and analyzed by GC as described above. All tests were done in triplicate using different matrices.

173 signal to noise ratio of 3:1 and of 6:1, respectively. 


\subsection{Statistical analyses}

176

The results from mycotoxin analyses were subjected to statistical analysis using 178 STAGRAPHICS PLUS software (Statistical Graphics Corp. version 5.1) and SPSS 179 (version 14.0.1 for Windows, SPSS Inc., Chicago). The toxin content data were checked 180 for normal distribution (Shapiro-Wilks test) and variance homogeneity (Cochran test).

181 As the data did not fulfill these conditions, it was subsequently subjected to the KruskalWallis test. When comparing the toxin levels in the different sample groups, the MannWhitney U-test applied to ranks was used to determine the statistical significance of the

184 differences. The toxin incidence data were also analyzed in order to establish a 185 significant association between different sample groups and the presence of mycotoxin 186 (Fisher's test). A probability value of 0.05 was used to determine the statistical 187 significance.

188

189 3. Results and discussion

190

\subsection{Analytical quality control}

192

193 Mycotoxins were quantified by an internal calibration procedure. Calibration curves

194 with internal standard were linear from 0.05 to $5 \mathrm{mg} / \mathrm{l}$ for DON and NIV (regression 195 coefficients $r=0.9993$ and $r=0.9990$ for DON and NIV, respectively). The estimated 196 limits of detection and quantification were 14.4 and $25.4 \mu \mathrm{g} / \mathrm{kg}$, respectively, for DON, 1979.6 and $15.9 \mu \mathrm{g} / \mathrm{kg}$ for NIV. 
The recoveries of DON and NIV in different samples are summarized in Table 1.

199 The recoveries of mycotoxins at the lower spiking level varied between $102.7 \%$ and $200107.3 \%$ for DON and $93.0 \%$ to $113.2 \%$ for NIV. At the higher spiking level, the 201 recoveries varied between $70.5 \%$ and $97.0 \%$ for DON and $77.9 \%$ and $94.1 \%$ for NIV. 202 The lowest recoveries corresponded to fried corn snack samples. These differences 203 could be attributable to the differences of matrix as described by Jestoi et al. (2004) and 204 it is possible that specific extraction analysis protocols should be used for each combination of mycotoxin and food. The $\mathrm{RSD}_{\mathrm{r}}(\%)$ of the mean recoveries for DON ranged from $2.2 \%$ at the higher spiking level to $12.8 \%$ at the lower spiking level, whereas these values for NIV varied between $0.3 \%$ and $19.5 \%$, both at the lower

208 spiking level. The recovery and $\mathrm{RSD}_{\mathrm{r}}$ obtained for DON are in line with the legislation 209 levels for the DON determination methods (EC, 2005b) thus the method is acceptable according to EU criteria. Specific measures for NIV have not been considered by legislation because a certain degree of co-occurrence with DON is generally observed.

\subsection{Occurrence of DON and NIV in corn-based foods}

The results obtained from the analysis of DON and NIV in the samples are DON.

The incidence of DON and NIV in all the samples was $26.8 \%$ and $4 \%$, respectively,

219 while the median content of the positive samples was 53.9 and $60.2 \mu \mathrm{g} / \mathrm{kg}$. The occurrence of DON varied between $25.5 \%, 27.6 \%$ and $46.8 \%$ for fried snacks, baked snacks and breakfast cereals, respectively. The incidence of DON was significantly different in breakfast cereals $(P=0.026)$. With regard to NIV occurrence, $3.4 \%$ of the 
223 breakfast cereals and $0.6 \%$ of the baked snack samples were contaminated by this 224 mycotoxin, while no fried snack samples was contaminated with NIV. The statistical analyses showed a significant dependence between the type of food and the presence of NIV at the $99 \%$ confidence level $(P=0.006)$.

The DON contamination levels varied from 30.1 to $121.1 \mu \mathrm{g} / \mathrm{kg}$ in breakfast cereals, from 36.4 to $131.7 \mu \mathrm{g} / \mathrm{kg}$ in baked snacks, and from 26.1 to $80.4 \mu \mathrm{g} / \mathrm{kg}$ in fried snacks. No significant differences were found among the median DON contents for all food items $(P>0.05)$. The highest level of DON was found among the baked snack samples $(131.7 \mu \mathrm{g} / \mathrm{kg})$ but no samples exceeded the legally established DON limit (500 $\mu g / k g)(E C, 2005 a)$.

The NIV contamination levels fluctuated between 51.1 and $106.5 \mu \mathrm{g} / \mathrm{kg}$ in breakfast cereals. Only one sample of baked snacks was contaminated with NIV (55.7 $\mu \mathrm{g} / \mathrm{kg})$. No significant differences were found among the median NIV contents for all positive food items $(P>0.05)$. The results show the natural co-occurrence of both toxins in two samples at concentrations of $64.9 \mu \mathrm{g} / \mathrm{kg}$ of DON and $55.7 \mu \mathrm{g} / \mathrm{kg}$ of NIV for a baked snack sample, and of 35.6 and $106.5 \mu \mathrm{g} / \mathrm{kg}$, respectively, for a breakfast cereal sample.

Comparison between Spanish surveillance and literature data indicates that the incidence of DON contamination in Spanish corn-based foods is lower than in similar foods analyzed in Italy (64\% of breakfast cereals and 93\% of maize-based foodstuffs)

242 (Cirillo et al., 2003a,b), Germany (67\% of breakfast cereals) (Schollenberger et al., 243 2005b), and the United Kingdom (35\% of breakfast cereals and 83.3\% of snacks) (FSA, 244 2005). Differences between these data and the results of the present study may be 245 attributed, among others, to a different origin of basing corn; it is well known that cereal 246 infection with Fusarium and toxin production depend strongly on environmental 247 conditions (damp climate, cool temperatures). Fusarium and trichothecene 
contamination is more likely under the wet and cold weather conditions of Northern and

249 Central European regions. This would explain the relative low percentage of DON/NIV 250 positive samples. Moisture levels during harvest, transporting and storing the grain, and

251 differences in food production methods (Larsen et al., 2004; Cavaliere et al., 2005) are 252 also believed to be contributing factors. Conversely however, Spanish corn-based 253 contamination is greater than that reported by Milanez et al. (2006) in Brazil, where 254 only one out of 78 samples of corn-based products (cornflakes, corn grits) was found to 255 present traces of DON and NIV. This may attribute either to a different origin of corn, 256 as mentioned above, or to the high detection and quantification limits estimated by the authors (40 and $170 \mu \mathrm{g} / \mathrm{kg}$ for DON and 40 and $200 \mu \mathrm{g} / \mathrm{kg}$ for NIV).

With regard to the median mycotoxin levels detected in this study, they were similar to both those found in Italy by Cirillo et al. (2003a,b) and in Germany by Schollenberger et al. (2005b), but lower than those registered in samples surveyed in the United Kingdom (FSA, 2005). The results from a previous study on the occurrence of Fusarium toxins in 25 samples of corn-based foods marketed in Spain (Cerveró et al., 2007) showed a higher incidence of deoxynivalenol (68\%) and mean content (91 $\mu \mathrm{g} / \mathrm{kg})$ of DON. This discrepancy between these data and present results may partly be attributed to the limited number of samples analyzed in the former study.

According to the information on the package, samples have been classified into two groups to associate mycotoxin incidence and content with the presence of additional ingredients: (1) samples with additional ingredients (92 samples), (2) samples without

269 additional ingredients (83 samples). The percentage of positive samples and the content of toxins are listed in Table 3. The occurrence of DON and NIV was similar for both 271 groups of samples, and the Fisher exact test showed no association between the 272 variables considered ( $P=0.225$ for DON; $P=0.182$ for NIV). The median content of 
273 DON was significantly higher in samples without additional ingredients $(63.7 \mu \mathrm{g} / \mathrm{kg})(P$ $274=0.004)$, while no significant differences were found for the median NIV content, 275 although the highest levels of mycotoxins were detected in samples with additional 276 ingredients. Moreover, fifty per cent of samples containing another type of cereal 277 (wheat or oats) presented detectable levels of DON. The highest level of NIV was 278 detected in one sample containing oats. It was clear from this work that contamination 279 by DON and NIV is not only exclusive of corn, but also of oat and wheat contents as 280 some authors have reported for these ingredients (Müller et al., 1997, 1998, 2001; 281 Langseth and Rundberget 1999; Schollenberger et al., 2002, 2005a,b).

282 In the same way, samples were classified into two groups to compare mycotoxin 283 occurrence and content according to the commercial brand: (1) private label (52 samples), and (2) company brand (123 samples). The results of the occurrence and 285 levels of toxins are shown in Table 3. Approximately $37 \%$ of private label brand 286 samples and $22.7 \%$ of company brand samples were positive for DON. With regard to NIV occurrence, $7.7 \%$ of the private brands and $2.4 \%$ of the company brands were 288 contaminated with this mycotoxin. The statistical study showed a weak association 289 between DON occurrence and type of commercial brand $(P=0.047)$ while no significant association was found for NIV. The statistical comparison between the mycotoxin level for both sample groups indicated no significant differences between the levels of both mycotoxins $(P=0.259)$. Although private labels have been seen as low293 priced and low-quality products in a social context, the results obtained herein indicate 294 that the quality of both types of commercial brands, in terms of mycotoxin content, is 295 approximately the same. In recent years, a significant increase in private label brands has been observed, and companies have started using them to market higher quality 
297 products. Nowadys in Europe, private label goods account for around 45\% of the 298 products sold in supermarkets.

299 In order to assess the public health risk of consuming DON and NIV in the Spanish

300 population, the exposure of consumers to these toxins can be compared to safety 301 guidelines, such as the Tolerable Daily Intake (TDI). Table 4 shows the calculated

302 human DON and NIV intake from the mean mycotoxin levels found in the samples analyzed in this study. The relationship between each mycotoxin intake and the TDI 304 levels proposed by the SCF of the European Union $(1 \mu \mathrm{g} / \mathrm{kg}$ bw/day for DON and 0.7 $305 \mu \mathrm{g} / \mathrm{kg}$ bw/day - temporary TDI for NIV), has been expressed as a percentage. The 306 mycotoxin intake values found in this study are less than those proposed in the TDI for 307 the respective toxin, and they represented a fraction which does not exceed $7.1 \%$ for 308 adults. However, these percentages increase to $12 \%$ for DON and $15.7 \%$ for NIV for 309 risk groups, such as children. The results of a large-scale European study on the occurrence of Fusarium toxins and dietary intake in the European population (EC,

311 2003) demonstrated that while the dietary intakes of DON and NIV were often less than

312 the TDI's for the respective toxin for the entire population and adults, higher intakes 313 values were observed for infants and children.

314 Overall, although the mycotoxin levels found in this survey were low, it is 315 important, however, to bear in mind that cereals are only one of the many possible 316 sources of these mycotoxins for humans, specially children or young people. Moreover,

317 Fusarium contamination in grains may differ among the years of harvest (Langseth and

318 Elen, 1997; Müller et al., 1997, 2001; Scott, 1997). Thus, different levels of toxin 319 contamination can also be expected for cereal-based foods.

320 Although longer extensive studies including more Fusarium toxins are advisable, 321 the results of the present study provide evidence of the presence of these mycotoxins in 
322 the corn-based foods marketed in Spain. This study confirms the importance of

323 continued surveillance of mycotoxin occurrence in cereal-processed foods in Spain, 324 especially if they are mainly consumed by children and young people. A considerable 325 contribution of these products to Fusarium toxin intake of the Spanish consumers may 326 be assumed.

\section{Acknowledgment}

329

This work has been financed by the Spanish Comisión Interministerial de Ciencia y

Tecnología (Project Ref. AGL2004-07549-C05-04) whose support is gratefully acknowledged.

\section{References}

Cavaliere, C., D’Ascenzo, G., Foglia, P., Pastorini, E., Samperi, R., Laganá, A., 2005. Determination of type B trichothecenes and macrocyclic lactone mycotoxins in field contaminated maize. Food Chemistry 92, 559 - 568.

Cerveró, M.C., Castillo, M.A., Montes, R., Hernández, E., 2007. Determination of trichothecenes, zearalenone and zearalenols in commercially available corn-based fodds in Spain. Revista Iberoamericana de Micología 24, 52 - 55.

342 Cetin, Y., Bullerman, L.B., 2006. Confirmation of reduced toxicity of deoxynivalenol in extrusion-processed corn grits by the MTT bioassay. Journal of Agricultural and Food Chemistry 54, 1949 - 1955. 
346 Cirillo, T., Ritieni, A., Galvano, F., Amodio-Cocchieri, R., 2003a. Natural co347 occurrence of deoxynivalenol and fumonisins $\mathrm{B}_{1}$ and $\mathrm{B}_{2}$ in Italian marketed 348 foodstuffs. Food Additives and Contaminants 20, 566 - 571.

349 Cirillo, T., Ritieni, A., Visone, M., Amodio-Cocchieri, R., 2003b. Evaluation of 350 conventional and organic Italian foodstuffs for deoxynivalenol and fumonisins $\mathrm{B}_{1}$ and B2. Journal of Agricultural and Food Chemistry 51, 8128 - 8131.

352 Eskola, M., Boonzaaijer, G., van Osenbruggen, W.A., Rizzo, A., Tijmensen, G., 2001. 353 A study of the suitability of gas chromatography-electron capture detection for the analysis of deoxynivalenol in cereals. Mycotoxin Research 16, 73 - 90.

European Commission, 2003. Collection of occurrence data of Fusarium toxins in food and assessment of dietary intake by the population of EU member states, Report on Tasks for Scientific Cooperation (SCOOP) 3.2.10 European Commission, Brussels. http://europa.eu.int/comm/food/fs/scoop/task3210.pdf.

European Commission, 2005a. Commission Regulation (EC) No. 856/2005 of 6 June 2005 amending Regulation (EC) No 466/2001 as regards Fusarium toxins. Official Journal of European Union L 143, 3 - 8.

362 European Commission, 2005b. Commission Directive No. 2005/38/EC of 6 June 2005 363 laying down the sampling methods of analysis for the official control of the levels of Fusarium toxins in foodstuffs. Official Journal of European Union L 143, 18 26.

FSA, 2003. Survey of retail cereal products for trichothecenes and zearalenone. Food Survey Information Sheet 35/03.

FSA, 2005. Survey of maize-based retail products for mycotoxins. Food Survey Information Sheet 72/05. 
Hazel, C.M., Patel, S., 2004. Influence of processing on trichothecene levels. Toxicology Letters 153, $51-59$.

Hussein, H.S., Brasel, J.M., 2001. Toxicity, metabolism and impact of mycotoxins on humans and animals. Toxicology 167, $101-134$.

Jestoi, M., Ritieni, A., Rizzo, A., 2004. Analysis of the Fusarium mycotoxins fusaproliferin and trichothecenes in grains using gas chromatography-mass spectrometry. Journal of Agricultural and Food Chemistry 52, 1464 - 1469.

Joint FAO/WHO Expert Committee on Food Additives (JECFA), 2000. Safety evaluation of certain food additives and contaminants. Zearalenone. WHO Food Additives Series 44 . http://www.inchem.org/documents/jecfa/jecmono/v44jec14.htm

Joint FAO/WHO Expert Committee on Food Additives (JECFA), 2001. Safety 382 evaluation of certain mycotoxins in food. Deoxynivalenol, HT-2 and T-2 toxin. FAO Food and Nutrition Paper 74. http://www.inchem.org/documents/jecfa/jecmono/v47je01.htm

388 Langseth, W., Rundberget, Th., 1999. The occurrence of HT-2 toxin and other 389

Larsen, J.C., Hunt, J., Perrin, I, Ruckenbauer, P., 2004. Workshop on trichothecenes trichothecenes in Norwegian cereals. Mycopathologia 147, 157-165. with a focus on DON: summary report. Toxicology Letters 153, 1 - 22.

Milanez, T.V., Valente-Soares, L.M., Baptista, G.G., 2006. Occurrence of trichothecene mycotoxins in Brazilian corn-based food products. Food Control 17, 293 - 298. 
Müller, H.M., Reimann, J., Schumacher, U., Schwadorf, K., 1997. Fusarium toxins in wheat harvested during six years in an area of southwest Germany. Natural Toxins $5,24-30$.

Müller, H.M., Reimann, J., Schumacher, U., Schwadorf, K., 1998. Natural occurrence of Fusarium toxins in oats harvested during five years in an area of southwest Germany. Food Additives and Contaminants 15, 801 - 806.

Müller, H.M., Reimann, J., Schumacher, U., Schwadorf, K., 2001. Further survey of the 401 occurrence of Fusarium toxins in wheat grown in southwest Germany. Archives of Animal Nutrition 54, $173-182$.

Placinta, C.M., D’Mello, J.P.F., Macdonald, A.M.C., 1999. A review of worldwide contamination of cereal grains and animal feed with Fusarium mycotoxins. Animal Feed Science and Technology 78, 21 - 37.

Samar, M., Resnik, S.L., González, H.H.L., Pacin, A.M., Castillo, M.D., 2007. 407 Deoxynivalenol reduction during the frying process of turnover pie covers. Food Control 18, $1295-1299$.

Schollenberger, M., Drochner, W., Rüfle, M., Suchy, S., Terry-Jara, H., Müller, H.M., 2005a. Trichothecene toxins in different groups of conventional and organic bread of the German market. Journal of Food Composition and Analysis 18, 69 - 78.

Schollenberger, M., Jara, H.T., Suchy, S., Drochner, W., Müller, H.M., 2002. Fusarium

Schollenberger, M., Müller, H.M., Rüfle, M., Suchy, S., Planck, S., Drochner, W., 2005b. Survey of Fusarium toxins in foodstuffs of plant origin marketed in Germany. International Journal of Food Microbiology 97, 317 - 326. 
418 Schollenberger. M., Müller, H.M., Rüfle, M., Terry-Jara, H., Suchy, S., Planck, S.,

419 Drochner, W., 2007. Natural occurrence of Fusarium toxins in soy food marketed in 420 Germany. International Journal of Food Microbiology 113, 142 - 146.

421 Scientific Committee on Food, 1999. Opinion on Fusarium Toxins - Part 1: 422 Deoxynivalenol (DON) (expressed on 2 December 1999). 423 http://europa.eu.int/comm/food/fs/sc/scf/out44_en.pdf

424 Scientific Committee on Food (SCF), 2000. Opinion on Fusarium Toxins - Part 4: 425 Nivalenol (NIV) (expressed on 19 October 2000). http://europa.eu.int/comm/food/fs/sc/scf/out74_en.pdf

Scientific Committee on Food (SCF), 2002. Opinion on Fusarium Toxins - Part 6: Group evaluation of T-2 toxin, Ht-2 toxin, nivalenol and deoxynivalenol (expressed on 26 February 2002). http://europa.eu.int/comm/food/fs/sc/scf/out123_en.pdf

Scott, P.M., 1991. Possibilities of reduction or elimination of mycotoxins present in 431 cereal grains. In: Chelkowsky, J. (Ed.), Cereal grain: Mycotoxins, fungi and quality in drying and storage. Elsevier, Amsterdam, pp. 529 - 572.

Scott, P.M., 1997. Multi-year monitoring of Canadian grains and grain-based foods for trichothecenes and zearalenone. Food Additives and Contaminants 14, 333 - 339.

Tanaka, T., Yamamoto, S., Hasegawa, A., Aoki, N, Besling, J.R., Sugiura, Y., Ueno, 436 Y., 1990. A survey of the natural occurrence of Fusarium mycotoxins, deoxynivalenol, nivalenol and zearalenone, in cereal harvested in the Netherlands.

439 Trucksess, M.W., Thomas, F., Young, K. Stack, M.E., Fulguers W.J., Page, S.W., 1995. 440 Survey of deoxynivalenol in US 1993 wheat and barley crop by enzyme-linkedimmunosorbment-assay. Journal of AOAC International 78, $631-636$. 
443 Table 1

444 Relation of analyzed samples according to different categories

\begin{tabular}{|c|c|c|c|c|c|}
\hline & \multicolumn{2}{|c|}{ Commercial brand } & \multicolumn{2}{|c|}{ Additional Ingredients ${ }^{\mathrm{a}}$} & \multirow{2}{*}{ Total } \\
\hline & Company brand & Private label & With & Without & \\
\hline Breakfast cereals & 25 & 30 & 30 & 25 & 55 \\
\hline Baked corn snacks & 49 & 8 & 29 & 28 & 57 \\
\hline Fried corn snacks & 49 & 14 & 33 & 30 & 63 \\
\hline
\end{tabular}

445 a: Samples with or without another ingredients such as chocolate, butter, honey, wheat, oat, and aromatic flavours. 
Table 2

453 Recoveries and relative standard deviations (\%) for trichothecenes in spiked samples ${ }^{a}$

\begin{tabular}{|c|c|c|c|c|}
\hline & Spiking levels $(\mu \mathrm{g} / \mathrm{kg})$ & Breakfast cereals & Baked corn snacks & Fried corn snack \\
\hline \multirow{3}{*}{ DON } & 1000 & $94.7 \pm 10.7$ & $97.0 \pm 12.8$ & $70.5 \pm 7.3$ \\
\hline & 500 & $95.2 \pm 4.2$ & $100.2 \pm 6.6$ & $94.9 \pm 4.9$ \\
\hline & 50 & $107.3 \pm 2.2$ & $106.7 \pm 8.8$ & $102.7 \pm 2.3$ \\
\hline \multirow{3}{*}{ NIV } & 2000 & $94.1 \pm 8.5$ & $93.2 \pm 18.7$ & $77.9 \pm 4.7$ \\
\hline & 1000 & $96.8 \pm 4.1$ & $105.4 \pm 9.7$ & $106.2 \pm 9.7$ \\
\hline & 300 & $93.0 \pm 7.8$ & $113.2 \pm 19.5$ & $101.6 \pm 0.3$ \\
\hline
\end{tabular}

${ }^{\mathrm{a}}:$ Number of samples $=3$ 
Table 3

Natural occurrence of mycotoxins in corn-based foods

\begin{tabular}{lcccc}
\hline & & & \multicolumn{2}{c}{ Toxin in positive samples $(\mu \mathrm{g} / \mathrm{kg})$} \\
\cline { 3 - 4 } & & & & \\
& Mycotoxin & Samples positive/total (\%) & Range & Median \\
\hline Breakfast cereals & DON & $22 / 55(40.0)$ & $30.1-121.1$ & 44.5 \\
& NIV & $6 / 55(11.0)$ & $51.1-106.5$ & 67.8 \\
Baked snacks & DON & $13 / 57(22.8)$ & $36.4-131.7$ & 62.5 \\
& NIV & $1 / 57(1.7)$ & 55.7 & 55.7 \\
Fried snacks & DON & $12 / 63(18.2)$ & $26.1-80.4$ & 55.5 \\
& NIV & $0 / 63$ & & - \\
\hline Total samples & DON & $47 / 175(26.8)$ & $26.1-131.7$ & 53.9 \\
& NIV & $7 / 175(4.0)$ & $51.1-106.5$ & 60.2 \\
\hline
\end{tabular}




\section{Table 4}

463 Natural occurrence of mycotoxins in corn-based foods according to their composition

\begin{tabular}{|c|c|c|c|c|}
\hline & \multirow[b]{2}{*}{ Mycotoxin } & \multirow[b]{2}{*}{ Samples positive/total (\%) } & \multicolumn{2}{|c|}{ Toxin in positive samples $(\mu \mathrm{g} / \mathrm{kg})$} \\
\hline & & & Range & Median \\
\hline \multirow[t]{2}{*}{ With additional ingredients } & DON & 22/92 (23.9) & $26.4-131.7$ & 38.7 \\
\hline & NIV & 2/92 (2.2) & $51.0-106.5$ & 78.7 \\
\hline \multirow[t]{2}{*}{ Without additional ingredients } & DON & 25/83 (30.1) & $34.8-105.7$ & 63.7 \\
\hline & NIV & $5 / 83(6.0)$ & $53.9-90.2$ & 60.2 \\
\hline
\end{tabular}


Table 5

471 Natural occurrence of mycotoxins in corn-based foods according to the type of commercial brand

\begin{tabular}{lcccc}
\hline & & & \multicolumn{2}{c}{ Toxin in positive samples $(\mu \mathrm{g} / \mathrm{kg})$} \\
\cline { 3 - 4 } & Mycotoxin & Samples positive/total (\%) & Range & Median \\
\hline Company brand & DON & $28 / 123(22.7)$ & $26.1-131.7$ & 59.7 \\
& NIV & $3 / 123(2.4)$ & $53.9-106.5$ & 55.7 \\
Private label brand & DON & $19 / 52(36.5)$ & $30.1-121.1$ & 46.7 \\
& NIV & $4 / 52(7.7)$ & $51.0-90.2$ & 67.8 \\
\hline
\end{tabular}

DON, deoxynivalenol; NIV, nivalenol 
Table 6

Estimated DON and NIV daily intake ( $\mu \mathrm{g} / \mathrm{kg} \mathrm{bw} / \mathrm{day})$ and the percentage that it represents of the proposed tolerable daily intake (TDI) by the Scientific Committee on Food of European Union (SCF)

\begin{tabular}{|c|c|c|c|c|c|c|c|}
\hline & & \multicolumn{3}{|c|}{ DON } & \multicolumn{3}{|c|}{ NIV } \\
\hline & & Mean level $(\mu \mathrm{g} / \mathrm{kg})$ & Intake ( $\mu \mathrm{g} / \mathrm{kg}$ bw/day) & SCF (\%) & Mean level $(\mu \mathrm{g} / \mathrm{kg})$ & Intake ( $\mu \mathrm{g} / \mathrm{kg}$ bw/day) & SCF (\%) \\
\hline \multirow[t]{2}{*}{ Breakfast cereals ${ }^{a}$} & Adults ${ }^{c}$ & 53.3 & 0.03 & 3.0 & 72.8 & 0.04 & 5.7 \\
\hline & Children $^{\mathrm{d}}$ & & 0.06 & 6.0 & & 0.09 & 12.8 \\
\hline Corn snacks ${ }^{b}$ & Children & & 0.12 & 12.0 & & 0.11 & 15.7 \\
\hline
\end{tabular}

481 DON, deoxynivalenol; NIV, nivalenol

$482{ }^{\text {a }}$ Recommended intake indicated on the label of the package ( $30 \mathrm{~g}$ ) is assumed.

$483{ }^{\mathrm{b}}$ A mean weight by package of $50 \mathrm{~g}$ is assumed.

$484{ }^{\mathrm{c}}$ A body weight (bw) of $60 \mathrm{~kg}$ is assumed for adults.

$485{ }^{\mathrm{d}}$ A body weight (bw) of $25 \mathrm{~kg}$ is assumed for children. 